\title{
Intralobar pulmonary sequestration associated with an aneurysmal aberrant aortic branch
}

Stefano Schena, MD, PhD, Traves D. Crabtree, MD, Jennifer Bell Zoole, BSN, and G. Alexander Patterson, MD, St Louis, Mo

丹 Supplemental material is available online.

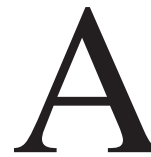

43-year-old woman, with no prior history of significant medical disease, presented with persistent vague chest discomfort and cough. A chest x-ray film showed a calcified mass in the left lower lobe, compatible with old granulomatous disease (Figure 1, A). However, a subsequent computed tomographic (CT) scan of the chest revealed a low-density lesion within the left lower lobe (Figure E1) with no evidence of surrounding parenchymal consolidation. A large feeding vessel, $2.5 \mathrm{~cm}$ in diameter, with a diffusely calcified wall was noted to arise from the lower thoracic aorta (Figure 1, B). Its course was better delineated on sagittal images and with a 3-dimensional reconstruction of a CT angiogram (Figures E2 and 2, A). The lower lobe mass had venous drainage to the left atrium. This anatomic relationship was compatible with an intralobar pulmonary sequestration. The patient underwent a left thoracotomy. There was no surgical plane between the mass and the

From the Division of Cardiothoracic Surgery, Washington University School of Medicine, St Louis, Mo.

Received for publication March 20, 2007; accepted for publication April 12, 2007.

Reprint requests: Traves D. Crabtree, MD, Division of Cardiothoracic Surgery, Washington University School of Medicine, 3108 Queeny Tower, One Barnes-Jewish Hospital Plaza, Saint Louis, MO 63110-1013 (E-mail: crabtreet@wudosis.wustl.edu).

J Thorac Cardiovasc Surg 2007;134:535-6

$0022-5223 / \$ 32.00$

Copyright $\odot 2007$ by The American Association for Thoracic Surgery doi:10.1016/j.jtcvs.2007.04.022 surrounding left lower lobe. The diagnosis of intralobar sequestration was confirmed by the intralobar position of the mass, a systemic arterial feeding vessel, and normal pulmonary venous drainage. After suture closure of the large feeding vessel (Figure 2, $B)$, a standard resection of the left lower lobe containing the sequestration completed the procedure. The postoperative course was uneventful, and the patient was discharged on the fifth postoperative day.

\section{Clinical Summary}

Pulmonary sequestration is a congenital abnormality characterized by a bronchopulmonary segment with an anomalous systemic arterial blood supply. There are two variants: intralobar and extralobar. The former is a lung segment contained within the normal visceral pleura and pulmonary parenchyma. In extralobar sequestration, the bronchopulmonary tissue is outside the visceral pleura and may be contained in its own pleural envelope.

Intralobar sequestration is most frequently diagnosed in the pediatric population and shows equal gender prevalence. It is rarely found in patients aged above 40 years. ${ }^{1,2}$ In the adult population, this lesion must be distinguished from the far more common neoplastic lesions, especially bronchogenic carcinoma. Up to $15 \%$ of patients, particularly in the adult population, do not have symptoms when the sequestration is discovered. ${ }^{3}$ Presentation varies from the incidental finding of a mass in an asymptomatic patient to symptoms of recurrent bronchitis or pneumonia. The diagnosis is usually obtained by CT scan, and the anatomy may be better defined using CT angiography or magnetic resonance angiography.

The pathogenesis of sequestration is the result of an accessory lung bud that develops from the ventral primitive foregut as it migrates caudally and receives systemic arterial supply instead of the normal pulmonary arterial supply. Some authors maintain that intralobar sequestration in older adults represents an acquired lesion related to bronchial obstruction, pneumonia, pulmonary

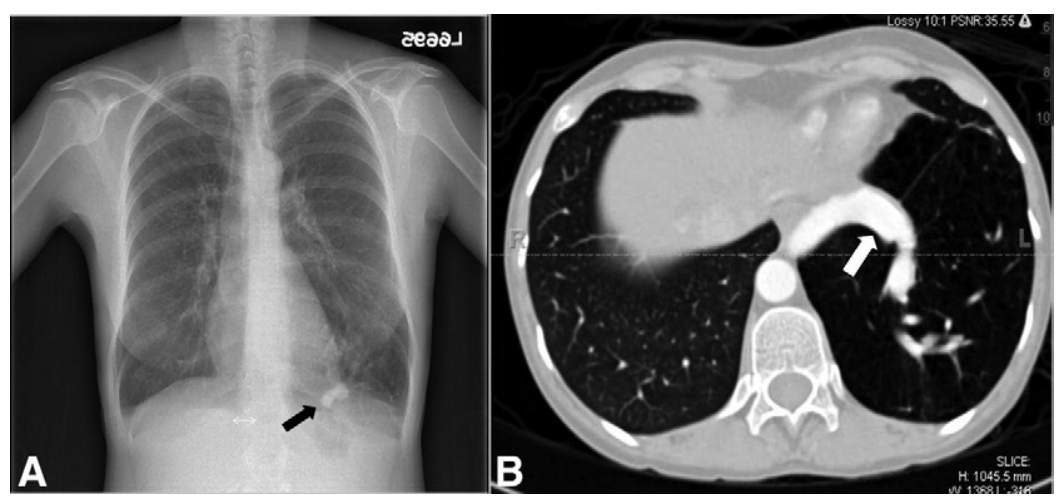

Figure 1. A, Chest x-ray film of an area of calcification (arrow) at the level of the left lower lobe. B, Chest CT scan demonstrating the large systemic arterial supply (arrow) to the intralobar mass. 


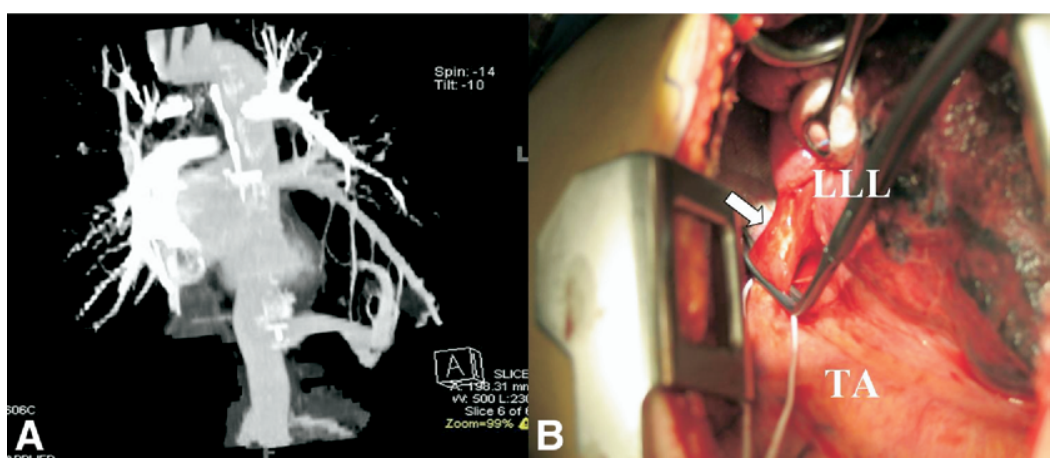

Figure 2. A, Chest CT angiogram, 3-dimensional reconstruction of the arterial branch course (arrow). B, Intraoperative photograph. Large arterial branch supplying the intralobar sequestration (arrow). TA, Thoracic aorta; LLL, left lower lobe.

artery occlusion, pleuritis, pulmonary ligament thickening, and parasitization of pulmonary ligament arteries. ${ }^{4}$

In approximately $95 \%$ of cases, the location is in the medial or posterior basal segments of the left lower lobe. Typically, there is no communication between the tracheobronchial tree and the sequestered lung. However, cases have been described in which there is a fistulous connection between the native tracheobronchial tree and the sequestered lung segment.

The systemic arterial supply derives predominantly from the descending thoracic aorta and less frequently from the abdominal aorta. Other derivations have been reported, including superior mesenteric artery and coronary circulation. Venous outflow is predominantly through the pulmonary venous system.

Resection by lobectomy (for intralobar) or sequestrectomy (for extralobar) should be performed at the time of diagnosis. These procedures can be conducted by open or video-assisted technique. ${ }^{5}$ Delaying surgery until infection or symptoms or signs of consolidation develop increases the morbidity of the operation. Preoper- ative delineation of the anomalous vasculature is fundamental in that it minimizes fatal outcomes from hemorrhage caused by accidental division of the systemic artery.

\section{References}

1. Turk LN 3rd, Lindskog GE. The importance of angiographic diagnosis in intralobar pulmonary sequestration. J Thorac Cardiovasc Surg. 1961; 41:299-305

2. Gustafson RA, Murray GF, Warden HE, Hill RC, Rozar GE. Intralobar sequestration: a missed diagnosis. Ann Thorac Surg. 1989;47:841-7.

3. Savic B, Birtel FJ, Tholen W, Funke HD, Knoche R. Lung sequestration: report of seven cases and review of 540 published cases. Thorax. 1979;34:96-101.

4. Stocker T, Malczak H. A study of pulmonary ligament arteries: relationship to intralobar pulmonary sequestration. Chest. 1984;86:611-5.

5. Klena JW, Danek SJ, Bostwick TK, Romero M, Johnson JA. Videoassisted thoracoscopic resection for intralobar pulmonary sequestration: single modality treatment with video-assisted thoracic surgery. J Thorac Cardiovasc Surg. 2003;126:857-9. 


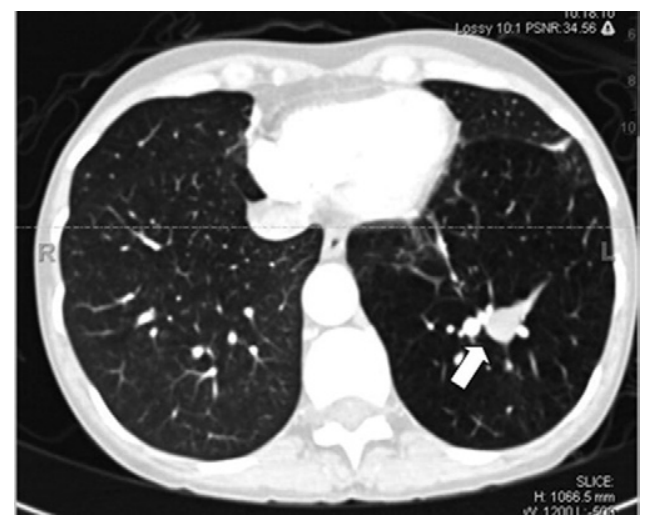

Figure E1. Chest CT scan confirming the presence of a mass within the left lower lobe (arrow).

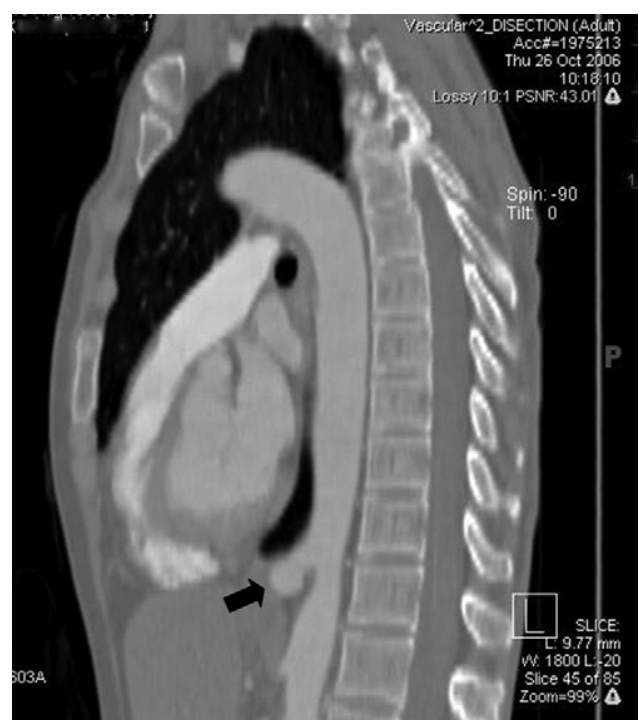

Figure E2. Chest CT scan, sagittal view showing the aneurysmatic nature of the arterial branch to the intrapulmonary sequestration (arrow). 